Journal Club

Editor's Note: These short reviews of recent JNeurosci articles, written exclusively by students or postdoctoral fellows, summarize the important findings of the paper and provide additional insight and commentary. If the authors of the highlighted article have written a response to the Journal Club, the response can be found by viewing the Journal Club at www.jneurosci.org. For more information on the format, review process, and purpose of Journal Club articles, please see http://jneurosci.org/content/ preparing-manuscript\#journalclub.

\title{
Rethinking the Role of Thought Suppression in Psychological Models and Treatment
}

\author{
(C) Caitlin S.M. Cowan, ${ }^{1}$ Shiu F. Wong, ${ }^{2}$ and Lillian Le ${ }^{2}$ \\ ${ }^{1}$ APC Microbiome Institute, University College Cork, Cork T12 YT20, Ireland, and 2School of Psychology, University of New South Wales, Sydney, 2052 New \\ South Wales, Australia \\ Review of Gagnepain et al.
}

Wouldn't it be nice to forget our deepest fears and cast aside our regrets? Unfortunately, for many individuals, it is precisely these unpleasant details that always seem to resurface. The repeated, distressing intrusion of unwanted thoughts and memories is a common feature of many psychological disorders (Wenzlaff and Wegner, 2000). Controlling or suppressing such intrusive thoughts is a demanding cognitive process that typically involves top-down inhibition of the hippocampus, a region known for its role in memory regulation, by prefrontal "control" regions (particularly the right dorsolateral prefrontal cortex [dlPFC]) (Anderson et al., 2016). However, not all intrusions are equal. Psychologically distressing intrusions have an added affective component, meaning that their suppression requires individuals to regulate their negative emotional response in addition

Received Sept. 1, 2017; revised 0ct. 10, 2017; accepted 0ct. 13, 2017.

This work was supported through the Joint Programming Initiative - A Healthy Diet for Healthy Life (JPI-HDHL) project HEALTHMARK by Science Foundation Ireland (SFI) 16/ERA-HDHL/3362. The APC Microbiome Institute was supported by SFI through the Irish Government's National Development Plan Grant 12/RC/2273. L.L. was supported by an Australian Government Research Training Program Scholarship. We thank Ryan Carceller for assistance with the figure.

The authors declare no competing financial interests.

Correspondence should be addressed to Dr. Caitlin S. M. Cowan, Laboratory of Neurogastroenterology, APC Microbiome Institute, Room 5.35, Biosciences Building, University College Cork, Cork, T12 YT20, Ireland. E-mail: caitlin.cowan@ucc.ie.

DOI:10.1523/JNEUROSCI.2511-17.2017

Copyright $\odot 2017$ the authors $\quad 0270-6474 / 17 / 3711293-03 \$ 15.00 / 0$ to controlling the intrusion per se. In a recent article in The Journal of Neuroscience, Gagnepain et al. (2017) sought to determine whether the cognitive and affective components of thought suppression are achieved through similar or distinct neural networks.

In that study, functional connectivity during a thought suppression task was assessed in healthy young adults $(N=24)$ using fMRI. First, participants learned associations between images of faces paired with neutral or aversive scenes. Next, in the scanner, participants were shown the face-cues at random. On half the trials, they were instructed to consciously recall the paired scene in detail; on the remaining trials, they were instructed to engage in thought suppression by blocking thoughts of the paired scene and instead blanking their mind while fixating on the face cue. Throughout the task, participants reported whether the paired scene came to mind during the trial. Finally, participants underwent an associative recognition test and rated the emotional valence of each of the original scenes.

Using dynamic causal modeling and Bayesian model selection, Gagnepain et al. (2017) identified the direction of communication between a network of brain regions that were differentially activated during thought suppression. The final model supported the hypothesis that suppression involves a top-down process driven by a frontoparietal network, including the dIPFC and other frontal regions. Furthermore, this inhibitory frontoparietal network downregulated both hippocampal and amygdalar activity in a manner suggesting parallel regulation of memories and associated emotional responses. The authors also observed individual differences in suppression ability that correlated with engagement of this neural "suppression network." That is, effective suppressors, who reported low rates of intrusions, exhibited stronger coupling in the suppression network during the task (i.e., higher inverse correlation between activity in the frontoparietal regions and activity in the hippocampus and amygdala). These individuals also exhibited greater levels of affect suppression (i.e., diminished negative affect for suppressed aversive scenes in the test phase). In contrast, ineffective suppressors reported frequent intrusions during suppression trials, exhibited weaker coupling between regions in the suppression network, and rated aversive scenes as more negative after (attempted) suppression.

Based on these findings, the authors proposed that individual differences in thought suppression may reflect vulnerability to psychopathology and that training in effective thought suppression may enhance psychological treatment outcomes. This proposal, although appealing, first needs to be considered in the 
context of established psychological models that have long characterized thought suppression as a key maintaining factor across a range of disorders, notably obsessive-compulsive disorder (OCD) and posttraumatic stress disorder (PTSD).

OCD is characterized by the presence of recurrent and persistent intrusive thoughts, images, or impulses that cause marked anxiety and distress (American Psychiatric Association, 2013). Similarly, intrusive thoughts about an experienced trauma are a hallmark symptom of PTSD that causes significant psychological distress (American Psychiatric Association, 2013). Cognitive-behavioral models suggest that this distress arises due to negative interpretations of intrusive thoughts as personally significant and dangerous (Fig. 1). For example, an individual with OCD may believe that having an intrusive thought (e.g., "I'm going to kill someone") increases the likelihood of the action occurring, making the individual personally responsible for their thoughts and causing guilt and anxiety (Salkovskis, 1985). In PTSD, intrusive memories of the trauma often induce fear if the intrusion is interpreted as a signal that the individual is under current threat (Ehlers and Clark, 2000).

It should be unsurprising that individuals who experience intrusive thoughts as highly distressing may attempt to suppress these thoughts as a strategy to regulate their negative emotional response. Unfortunately, it seems that thought suppression can lead to paradoxical increases in the frequency of intrusions and the intensity of associated distress, a phenomenon known as the rebound effect that is observed across a variety of clinical conditions (e.g., Purdon et al., 2005; Nickerson et al., 2016). In addition to the negative cycle created by rebound effects, failed attempts at thought suppression (i.e., ineffective control) can also exacerbate psychological symptoms by reinforcing negative interpretations of intrusions. Specifically, individuals fail to learn that intrusions are nonthreatening, preventing extinction of negative beliefs. In PTSD, suppression of trauma-related intrusions can further prevent elaborate processing of the trauma into memory, thus maintaining psychological symptoms (Foa and Kozak, 1986). Supporting this model, thought suppression is more frequent in clinical populations (Magee et al., 2012) and high thought suppression is predictive of increased symptom severity at later time points (e.g., Mayou et al., 2002; Wenzlaff and Luxton, 2003).

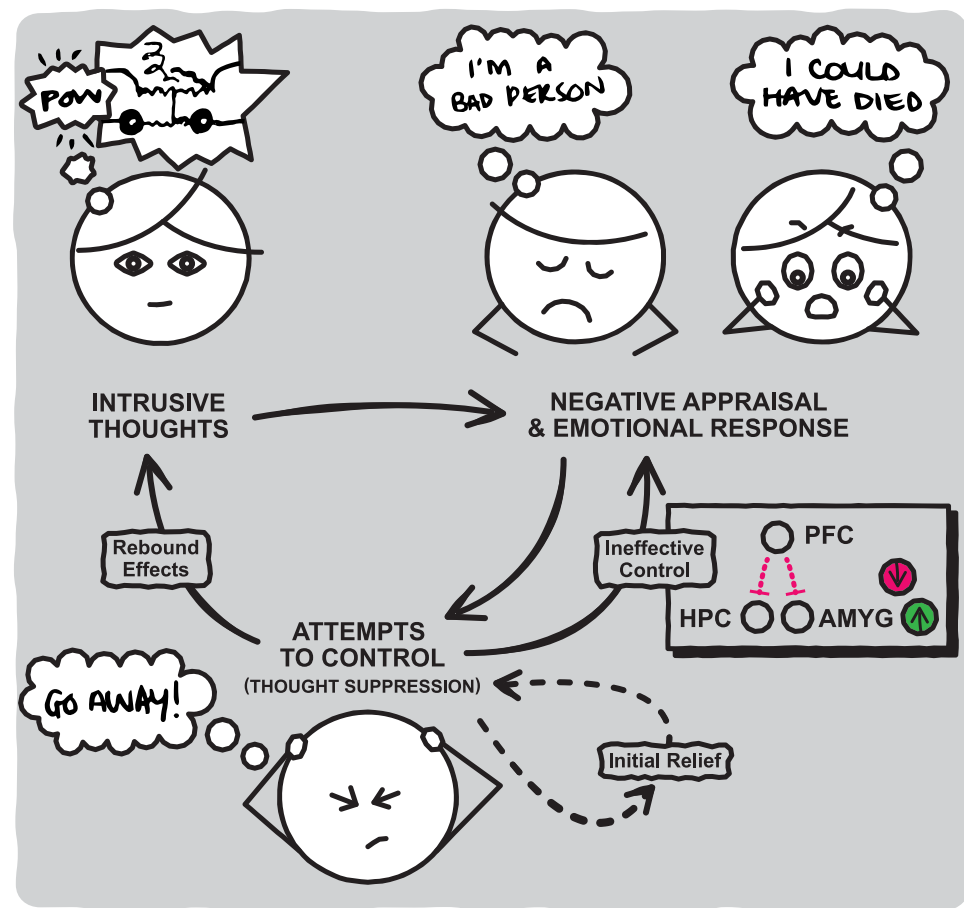

Figure 1. A cognitive-behavioral model of thought suppression as a maintaining factor in psychopathology. It is proposed that intrusive thoughts and memories evoke negative emotional responses (sadness, anxiety, fear) due to negative appraisals or interpretations of the meaning of the intrusions. The use of thought suppression to regulate negative emotions may bring some initial, short-lasting relief but often has detrimental long-term effects. These include a paradoxical increase in the frequency of intrusive thoughts (rebound effects) and strengthening of negative appraisals when thought suppression fails (ineffective control). The results of Gagnepain et al. (2017) suggest that weak connectivity between the PFC and medial temporal lobe structures (hippocampus [HPC]; amygdala [AMYG]) may contribute to ineffective control and individual differences in vulnerability to this negative cycle of suppression.

The findings of Gagnepain et al. (2017) suggest that some individuals, even in healthy populations, may be more vulnerable to the negative cycle depicted in Figure 1 due to underlying neurobiological differences that make them more likely to fail at thought suppression. There is some limited support for this hypothesis in the clinical literature. One study found that depressed women exhibit attenuated dIPFC activation during thought suppression compared with healthy women (Carew et al., 2013). Importantly, women at risk for depression (first-degree relative with depression) showed an intermediate dlPFC response, supporting the assertion that neurobiological differences signal risk rather than simply being consequences of the disorder. Although brain-imaging studies in OCD populations have produced inconsistent results (Menzies et al., 2008), there is some evidence for structural and functional changes in the suppression network in PTSD, including reduced volume of the hippocampus and anterior cingulate cortex, hyperactivity of the amygdala response to stress, and reduced prefrontal-amygdala connectivity (O’Doherty et al., 2015; Clausen et al.,
2017). Unfortunately, most of these clinical imaging studies have examined neurobiological differences only after diagnosis, making it difficult to determine directionality of effects. The findings of Gagnepain et al. (2017) suggest that more research is warranted to specifically examine functional connectivity during thought suppression across different psychological disorders, particularly prospective studies to determine whether functional abnormalities precede and predict symptom onset.

Another critical consideration for future research will be to establish the specificity of the present findings to thought suppression. The suppression network overlaps with networks underlying other emotion regulation strategies, such as cognitive reappraisal, a key component of cognitive-behavioral therapies used to break the suppression cycle by addressing negative interpretations of thoughts (Blechert et al., 2015). Reappraisal also increases frontal activation (including in the dlPFC) and decreases amygdala activation (Buhle et al., 2014). In a direct comparison of suppression and reappraisal, both strategies activated the same prefrontal regions, but this response was faster during reappraisal and 
only reappraisal inhibited amygdala responses (Goldin et al., 2008). Therefore, individual differences in connectivity in the suppression network might reflect the use of different emotion regulation strategies, perhaps due to differing interpretations of the instructions. For instance, if participants focused on the instruction to "block thoughts . . by blanking their mind," this would likely elicit thought suppression in the traditional sense; whereas if they focused on the instruction to "fixate ... on the facecue," this would likely elicit detailed examination of the cue in an objective manner more akin to reappraisal. Identifying precisely what is involved in effective thought suppression will be crucial to understanding whether it is possible to enhance performance in ineffective suppressors, and therefore whether thought suppression will be a useful therapeutic tool.

Finally, it will be important to determine whether the current findings apply under ecologically valid conditions relevant to individuals with psychological disorders. For example, high levels of stress are inherent to the experience of psychopathology (American Psychiatric Association, 2013). However, participants in the Gagnepain et al. (2017) experiments engaged in thought suppression in an artificial experimental environment free from any competing cognitive demands. This contrast is particularly important given evidence that intrusions occur more frequently under conditions of stress or high cognitive load (Wenzlaff and Wegner, 2000; Nixon et al., 2009). Another fundamental question is whether the benefits of successful thought suppression are enduring given that Gagnepain et al. (2017) only investigated short-term effects. Indeed, cognitive-behavioral models would predict that thought suppression leads to immediate relief from the distress associated with intrusions, but that these benefits are temporary and would diminish from overuse of this strategy (Fig. 1).
In conclusion, Gagnepain et al. (2017) demonstrated that suppression of intrusive memories and suppression of associated negative emotional responses are supported by parallel neural processes. Furthermore, they showed that engagement of these neural processes was related to individual differences in the effectiveness of both cognitive and emotional suppression, with interesting clinical implications. Their findings have led us to critically examine a priori beliefs around the negative impacts of thought suppression from a psychological perspective. Before incorporating this technique into psychological therapies, however, the mechanism of thought suppression should be clarified in future research.

\section{References}

American Psychiatric Association (2013) Diagnostic and statistical manual of mental disorders, Ed 5. Arlington, TX: American Psychiatric.

Anderson MC, Bunce JG, Barbas H (2016) Prefrontal-hippocampal pathways underlying inhibitory control over memory. Neurobiol Learn Mem 134:145-161. CrossRef Medline

Blechert J, Wilhelm FH, Williams H, Braams BR, Jou J, Gross JJ (2015) Reappraisal facilitates extinction in healthy and socially anxious individuals. J Behav Ther Exp Psychiatry 46: 141-150. CrossRef Medline

Buhle JT, Silvers JA, Wager TD, Lopez R, Onyemekwu C, Kober H, Weber J, Ochsner KN (2014) Cognitive reappraisal of emotion: a meta-analysis of human neuroimaging studies. Cereb Cortex 24:2981-2990. CrossRef Medline

Carew CL, Milne AM, Tatham EL, MacQueen GM, Hall GB (2013) Neural systems underlying thought suppression in young women with, and at-risk, for depression. Behav Brain Res 257:13-24. CrossRef Medline

Clausen AN, Francisco AJ, Thelen J, Bruce J, Martin LE, McDowd J, Simmons WK, Aupperle RL (2017) PTSD and cognitive symptoms relate to inhibition-related prefrontal activation and functional connectivity. Depress Anxiety 34:427-436. CrossRef Medline

Ehlers A, Clark DM (2000) A cognitive model of posttraumatic stress disorder. Behav Res Ther 38:319-345. CrossRef Medline

Foa EB, Kozak MJ (1986) Emotional processing of fear: exposure to corrective information. Psychol Bull 99:20-35. CrossRef Medline

Gagnepain P, Hulbert J, Anderson MC (2017)
Parallel regulation of memory and emotion supports the suppression of intrusive memories. J Neurosci 37 : 6423-6441. CrossRef Medline

Goldin PR, McRae K, Ramel W, Gross JJ (2008) The neural bases of emotion regulation: reappraisal and suppression of negative emotion. Biol Psychiatry 63:577-586. CrossRef Medline

Magee JC, Harden KP, Teachman BA (2012) Psychopathology and thought suppression: a quantitative review. Clin Psychol Rev 32:189 201. CrossRef Medline

Mayou RA, Ehlers A, Bryant B (2002) Posttraumatic stress disorder after motor vehicle accidents: 3-year follow-up of a prospective longitudinal study. Behav Res Ther 40:665675. CrossRef Medline

Menzies L, Chamberlain SR, Laird AR, Thelen SM, Sahakian BJ, Bullmore ET (2008) Integrating evidence from neuroimaging and neuropsychological studies of obsessivecompulsive disorder: the orbitofronto-striatal model revisited. Neurosci Biobehav Rev 32: 525-549. CrossRef Medline

Nickerson A, Garber B, Ahmed O, Asnaani A, Cheung J, Hofmann SG, Huynh L, Liddell B, Litz BT, Pajak R, Bryant RA (2016) Emotional suppression in torture survivors: relationship to posttraumatic stress symptoms and trauma-related negative affect. Psychiatry Res 242:233-239. CrossRef Medline

Nixon RD, Cain N, Nehmy T, Seymour M (2009) The influence of thought suppression and cognitive load on intrusions and memory processes following an analogue stressor. Behav Ther 40:368-379. CrossRef Medline

O'Doherty DC, Chitty KM, Saddiqui S, Bennett MR, Lagopoulos J (2015) A systematic review and meta-analysis of magnetic resonance imaging measurement of structural volumes in posttraumatic stress disorder. Psychiatry Res 232:1-33. CrossRef Medline

Purdon C, Rowa K, Antony MM (2005) Thought suppression and its effects on thought frequency, appraisal and mood state in individuals with obsessive-compulsive disorder. Behav Res Ther 43:93-108. CrossRef Medline

Salkovskis PM (1985) Obsessional-compulsive problems: a cognitive-behavioral analysis. Behav Res Ther 23:571-583. CrossRef Medline

Wenzlaff RM, Luxton DD (2003) The role of thought suppression in depressive rumination. Cognit Ther Res 27:293-308. CrossRef

Wenzlaff RM, Wegner DM (2000) Thought suppression. Annu Rev Psychol 51:59-91. CrossRef Medline 